\title{
Human Levels of MMP-1 in Degenerated Disks Can Be Mitigated by Signaling Peptides from Mesenchymal Stem Cells
}

\author{
Daphne Hingert ${ }^{a}$ Phonphan Nawilaijaroen $^{b}$ Karin Ekström ${ }^{c, d}$ \\ Adad Baranto $^{\text {a, e }}$ Helena Brisby ${ }^{\text {a, e }}$ \\ a Lundberg Laboratory for Orthopedic Research, Department of Orthopedics, Institute of Clinical Sciences, \\ Sahlgrenska Academy, University of Gothenburg, Gothenburg, Sweden; bepartment of Physics, Chalmers \\ University of Technology, Gothenburg, Gothenburg, Sweden; ' Sahlgrenska Cancer Center, Department of Surgery, \\ Institute of Clinical Sciences, Sahlgrenska Academy, University of Gothenburg, Gothenburg, Sweden; ${ }^{\text {WWallenberg }}$ \\ Centre for Molecular and Translational Medicine, University of Gothenburg, Gothenburg, Sweden; ${ }^{\text {eDepartment of }}$ \\ Orthopedics, Sahlgrenska University Hospital, Gothenburg, Sweden
}

\section{Keywords}

Conditioned media · Human mesenchymal stem cells ·

Intervertebral disk cells · Low back pain · MMP-1 · TIMP1

\begin{abstract}
Degradation of extracellular matrix (ECM) in intervertebral disks (IVDs) during IVD degeneration plays a vital role in low back pain (LBP). In healthy IVDs, synthesis and degradation of ECM are kept in balance by matrix metalloproteinases (MMPs) and tissue inhibitors of MMPs. MMPs are enzymes responsible for ECM degradation, and their expression levels are known to increase in degenerated disks. However, the exact pathophysiological concentration of MMP-1 in the degenerated disks of patients with chronic LBP has not been reported previously. Factors secreted by human mesenchymal stem cells (hMSCs) have shown positive results in cell therapy of degenerated disks. The aim of this study was to investigate the pathophysiological MMP-1 concentration (in $\mathrm{ng} / \mathrm{mL}$ ) in degenerated disk tissue and to evaluate if conditioned media (CM) from hMSCs could mitigate the effects of
\end{abstract}

MMP-1 at the detected levels in a 3D in vitro disk cell (DC) pellet model. Tissue levels of MMP-1 were quantified in disk tissue collected from 6 chronic LBP patients undergoing surgery. DC pellet cultures were performed to investigate the effects of MMP- 1 alone and the effects of conditioned media (CM) in the presence of MMP-1. MMP-1 was introduced in the pellets on day 14 at concentrations of 5,50 , or $100 \mathrm{ng} / \mathrm{mL}$. The pellets were harvested on day 28 and evaluated for cell viability, proliferation, and ECM production. The mean concentration of MMP-1 in disk tissue was $151 \mathrm{ng} / \mathrm{mL}$. Results from pellet cultures demonstrated a higher number of viable cells, glycosaminoglycan production, and ECM accumulation in the CM group even in the presence of MMP-1 compared to the controls. However, the level decreased with increasing MMP-1 concentration. The results demonstrated that $\mathrm{CM}$ has the ability to mitigate matrix degradation property of MMP- 1 up to $50 \mathrm{ng} / \mathrm{mL}$ suggesting that CM could potentially be used to treat early stages of disk degeneration.

(c) 2020 The Author(s)

Published by S. Karger AG, Basel
(C) 2020 The Author(s)

Published by S. Karger AG, Basel

This is an Open Access article licensed under the Creative Commons Attribution-NonCommercial-4.0 International License (CC BY-NC) (http://www.karger.com/Services/OpenAccessLicense), applicable to the online version of the article only. Usage and distribution for commercial purposes requires written permission.
Daphne Hingert

Department of Orthopedics, Institute of Clinical Sciences

Sahlgrenska Academy, University of Gothenburg

R-huset, Plan 7, Göteborgsvägen 31, SE-431 80 Mölndal (Sweden)

daphne.hingert@gu.se 


\section{Introduction}

Low back pain (LBP) is one of the most common conditions and is experienced by more than $80 \%$ of the western population during lifetime [Airaksinen et al., 2006]. It ranks higher than cancer and heart disease, for example, according to the Global Burden of Disease Study in terms of years lived with disability [van Hooff et al., 2014]. Intervertebral disk (IVD) degeneration (IVDD) is believed to be one of the major factors that initiates LBP. IVDD is characterized by degradation of extracellular matrix (ECM) by native enzymes, matrix metalloproteinases (MMPs) [Goupille et al., 1998; Roughley, 2004; Ekman et al., 2005]. Suggested biological treatments of degenerated disks include growth factors to stimulate the predominant habitant cells in the IVDs that maintain the ECM, mainly collagen type II (COLIIA1) and aggrecan [Johnson et al., 2015], or signaling peptides to inhibit the activity of degenerative MMPs [Pockert et al., 2009; Leckie et al., 2012; Zou et al., 2014].

Human mesenchymal stem cells (hMSCs) secrete powerful factors and extracellular vesicles with regenerative effects on many disease models [Somoza et al., 2014; Zeckser et al., 2016; Kay et al., 2017]. In fact, tissue inhibitor of MMP-1 (TIMP-1), an inhibitor of MMP-1, has been reported as a constituent of the hMSC secretome [Maffioli et al., 2017]. MMP-1 is a type of collagenase belonging to the MMP family that specifically degrades collagens in the IVDs. Higher MMP-1 levels have been associated with severe IVD degeneration in terms of gene expression [Vo et al., 2013; Deng et al., 2015; Wang et al., 2018; Zhang et al., 2018]; however, changes in MMP-1 concentrations in IVD tissue remain to be evaluated.

The first aim of the present study was to determine the concentration of MMP-1 in degenerated IVD tissue obtained from patients with chronic LBP. It is well known that conditioned media (CM) from hMSCs is proregenerative, and the second aim in this study was to investigate the ability of CM to combat the effects of MMP-1 on disk cells (DCs) at the concentrations detected in degenerated disk tissue of LBP patients in a 3D human in vitro model.

\section{Materials and Methods}

\section{Patients}

IVD tissue samples used for quantification of MMP-1 were obtained from 6 patients ( 3 males, 3 females; mean age $42 \pm 3$ years). The disks were graded according to the Pfirrmann grading system on a scale from 1 to 5 based on preoperatively obtained magnetic resonance imaging (MRI) (Table 1). Bone marrow aspirates and disk tissue for cell cultures were harvested from 3 patients ( 1 male and 2 females; mean age $37 \pm 6$ years). Disk tissue for cell culture was of grade 3-4 according to the Pfirrmann grading system on MRI. All the disk tissue collected was a mixture of annulus fibrosus and nucleus pulposus tissue due to the disintegration of the tissue types. All the patients were undergoing spinal fusion surgery due to IVD degeneration.

\section{Ethical Approval and Consent to Participate}

All human tissue/cells were collected with ethical approval by the Regional Ethical Review Board at the Sahlgrenska Academy, Gothenburg University, Gothenburg, Sweden (Dnr 532-04) and with informed consent from the patients.

\section{Quantification of MMP-1 Level in Disk Tissue}

Disk tissue was cut into small pieces with a scalpel. Two milliliters of PBS were added to $1 \mathrm{~g}$ of disk tissue, and the tubes were placed on a rotor. After $24 \mathrm{~h}$, the samples were centrifuged at 1,500 $\mathrm{rpm}$ at $4^{\circ} \mathrm{C}$ for $5 \mathrm{~min}$. The liquid phase was then analyzed with human MMP-1 ELISA kit (Abcam, Cambridge, UK). Absorbance was measured at $450 \mathrm{~nm}$ by a microplate reader (BioTek, VT, USA).

\section{hMSC Isolation and Cell Culture}

Bone marrow aspirate samples were collected in 3.2\% sodium citrate (Greiner Bio One, Kremsmuenster, Austria) after surgery and then aliquoted to Ficoll tubes (BD Vacutainer ${ }^{\circledR}$ CPT $^{\text {TM}}$; Biosciences, NJ, USA) for centrifugation at $1,500 \mathrm{rpm}$ for $20 \mathrm{~min}$. The middle phase was transferred and cultured in culture flasks (Corning, NY, USA) at $37^{\circ} \mathrm{C}$ and $5 \% \mathrm{CO}_{2}$ in MSC media (DMEM-low glucose with $110 \mathrm{mg} / \mathrm{L}$ sodium pyruvate, and $4 \mathrm{mmol} / \mathrm{L} \mathrm{L-gluta-}$ mine [Thermo Fisher Scientific, MA, USA] together with $1 \%$ penicillin/streptomycin, $10 \%$ human serum and $4 \mathrm{ng} / \mathrm{mL} \beta$-fibroblast growth factor). Media were changed every $48 \mathrm{~h}$, and the cells were passaged at $90 \%$ confluency.

\section{hMSC Characterization}

To characterize hMSCs, isolated cells were analyzed for CD73, CD90, and CD105 expression, and the absence of CD11b, CD19, CD34, CD45, and HLA/DR expression using BD Stemflow hMSC analysis kit (BD Biosciences, CA, USA). Cells were prepared according to the manufacturer's instructions, and data were acquired using a BD FACSVerse ${ }^{\mathrm{TM}}$ instrument (BD Biosciences) and analyzed using FlowJo ${ }^{\mathrm{TM}} 10$ (FlowJo; LLC, Ashland, OR, USA).

\section{hMSC CM Collection}

hMSCs from 3 patients were cultured in MSC media at a density of approximately 10,000 cells $/ \mathrm{cm}^{2}$ for 14 days, and CM was harvested every $48 \mathrm{~h}$. The collected CM was centrifuged at 1,500 $\mathrm{rpm}$ at $4{ }^{\circ} \mathrm{C}$ for $5 \mathrm{~min}$, the supernatants (from all 3 patients) were then pooled in order to even out the secretions from all the donor cells, sterile filtered (Sarstedt, Nümbrecht, Germany), and stored at $-80^{\circ} \mathrm{C}$ until use. All the hMSCs used in the study were in passages $4-5$.

\section{Disk Cell Isolation and Cell Culture}

Disk tissue was cut into small pieces and transferred to culture flasks (Corning) prior to the addition of $1 \mathrm{mg} / \mathrm{mL}$ type II collagenase. After incubation overnight at $37^{\circ} \mathrm{C}$ and $5 \% \mathrm{CO}_{2}$, the cell suspension was centrifuged at $1,500 \mathrm{rpm}$ at $4^{\circ} \mathrm{C}$ for $5 \mathrm{~min}$, and then cells were cultured at $37^{\circ} \mathrm{C}$ and $5 \% \mathrm{CO}_{2}$ in DC media (DMEM-low 
Table 1. Level of MMP-1 in disk tissue isolated from patients with degenerative disk disease

\begin{tabular}{llllll}
\hline Patients & Gender & $\begin{array}{l}\text { Age, } \\
\text { years }\end{array}$ & $\begin{array}{l}\text { Disks, } \\
n\end{array}$ & $\begin{array}{l}\text { Pfirrmann } \\
\text { grading }\end{array}$ & $\begin{array}{l}\text { MMP-1, } \\
\text { ng/mL }\end{array}$ \\
\hline Patient 1 & Male & 46 & 2 & Grade 4/5 & $84^{1}$ \\
Patient 2 & Male & 36 & 2 & Grade 5/5 & $150^{1}$ \\
Patient 3 & Male & 34 & 1 & Grade 5 & 216 \\
Patient 4 & Female & 49 & 2 & Grade 4/5 & $135^{1}$ \\
Mean \pm SEM & & & & Grade 4 & $151 \pm 24$ \\
Patient 5 & Female & 37 & 1 & Grade 3 & 74 \\
Patient 6 & Female & 46 & 1 & Grade 4 & 254 \\
& & & & & \\
\hline
\end{tabular}

The degenerative condition was assessed according to the Pfirrmann Disk Degeneration Grading System (scale from 1 to 5 ).

${ }^{1}$ Represents MMP-1 level of a sample with a mix of 2 disk tissues. glucose with $110 \mathrm{mg} / \mathrm{L}$ sodium pyruvate, $4 \mathrm{mmol} / \mathrm{L} \mathrm{L}$-glutamine (Thermo Fisher Scientific), 1\% penicillin/streptomycin, and 10\% human serum). The medium was changed every $48 \mathrm{~h}$, and DCs were passaged at $90 \%$ confluency. All DCs used in the study were in passage 5 .

\section{Three-Dimensional Pellet Culture}

Approximately 200,000 DCs were placed in a polypropylene conical tube (Corning) with $0.5 \mathrm{~mL}$ of relevant media. Cells were centrifuged at $1,500 \mathrm{rpm}$ at $4{ }^{\circ} \mathrm{C}$ for $5 \mathrm{~min}$ and incubated at $37^{\circ} \mathrm{C}$ and $5 \% \mathrm{CO}_{2}$. Medium was replaced every 2 days, and pellets were harvested on day 28. For each stimulation group per patient, 2 replicates of the pellets were used for histology and 2 for biochemical analysis ( $n=3$ with 2 technical replicates for each).

\section{Stimulation of Pellets with MMP-1 and CM}

Three stimulation groups were performed on DC pellets, namely the MMP-1, the CM + MMP-1, and the control group. Pellets in the MMP-1 group were cultured in chondrogenic media: DMEM-high glucose added with insulin, transferrin, and selenium (ITS-G; Thermo Fisher Scientific), $5 \mathrm{mg} / \mathrm{mL}$ linoleic acid, 10 $\mathrm{ng} / \mathrm{mL}$ transforming growth factor- $\beta$ (TGF- $\beta 1$; R\&D Systems, MN, USA), $14 \mathrm{mg} / \mathrm{mL}$ ascorbic acid , $10^{-7} \mathrm{M}$ dexamethasone (Sigma-Aldrich, MO, USA), $1.0 \mathrm{mg} / \mathrm{mL}$ human serum albumin (Equitech-Bio Inc., Kerrville, TX, USA), and 1\% penicillin/streptomycin). Based on the concentration of MMP-1 detected in disk tissue from patients diagnosed with degenerative disk disease, concentrations of 5, 50, or $100 \mathrm{ng} / \mathrm{mL}$ MMP-1 (R\&D Systems, Minneapolis, MN, USA) were selected and added to the pellet from days 14-28 during every media change. MMP-1 was added on day 14 in order to allow the cells to start producing matrix within the pellets before the matrix-degrading enzyme was added. Pellets in the $\mathrm{CM}+\mathrm{MMP}-1$ group were cultured in CM supplied with chondrogenic media in a 1:1 ratio to replenish the nutrients depleted. MMP-1 at concentrations of 5, 50, or $100 \mathrm{ng} / \mathrm{mL}$ were added on days 14-28. Pellets treated with chondrogenic media alone without addition of MMP-1 or CM served as controls.

\section{Cell Proliferation/Viability Measurement}

In order to study cell proliferation and viability, $50 \mu \mathrm{L}$ of the cell counting kit 8 (CCK-8) solution (Dojindo, Munich, Germany) were added to each pellet and incubated for $4 \mathrm{~h}$ at $37^{\circ} \mathrm{C}$ and $5 \%$
$\mathrm{CO}_{2} ; 100 \mu \mathrm{L}$ of the supernatant were collected from each pellet in duplicates and transferred to a 96-well plate, and absorbance was measured at $450 \mathrm{~nm}$ by a microplate reader (BioTek, Winooski, VT, USA). CCK- 8 was performed on days 14,21 , and 28 before harvesting of the pellets. The supernatant was collected in duplicates from the pellets for each stimulation group $(n=3$, with 2 technical replicates for each).

\section{Glycosaminoglycan and DNA Assays}

DC pellets were solubilized by the proteolytic enzyme papain (1.5 mg papain/mL; Sigma-Aldrich; $20 \mathrm{mM}$, sodium phosphate buffer, $1 \mathrm{mM}$ EDTA, and $2 \mathrm{mM}$ dithiothreitol) and incubated at $60^{\circ} \mathrm{C}$ overnight. The digested pellets were analyzed using a glycosaminoglycan (GAG) assay kit (Chondrex, Redmond, WA, USA), and DNA assay kit (Chondrex). The assays were performed according to the manufacturer's instruction. Absorbance was read at $525 \mathrm{~nm}$ for GAG concentration, and fluorescence was read at excitation $360 \mathrm{~nm} / \mathrm{emission} 460 \mathrm{~nm}$ for DNA. Analyses were run in duplicate, and data presented as GAG content normalized to total DNA for each pellet.

\section{Histological Staining}

Harvested DC pellets were fixed with $4 \%$ formaldehyde (Histolab, Gothenburg, Sweden) prior to sectioning. The sections were then stained with Alcian blue-Van Gieson, and the ECM components (proteoglycan and collagen) were evaluated under light microscopy (Nikon Eclipse E600). Analysis was conducted on 2 technical replicates per pellet for each stimulation group for each donor.

\section{Immunohistochemistry}

In order to evaluate the expression levels of aggrecan and COLIIA1, paraffin-embedded sections of DC pellets were deparaffinized and rehydrated in xylene and ethanol (99, 95, and 70\%), respectively. The samples were then incubated in $0.1 \mathrm{M}$ citrate buffer ( $\mathrm{pH} 6)$ at $90^{\circ} \mathrm{C}$ for $20 \mathrm{~min}$ for antigen retrieval. Primary antibodies, anti-aggrecan (1:500; Abcam, Cambridge, MA, USA) and anti-COLIIA1 (1:100, Abcam), were added and incubated overnight at $4{ }^{\circ} \mathrm{C}$. Blocking steps with $0.1 \%$ Triton X-100, $2 \%$ BSA, and $100 \mathrm{~mm}$ glycine in PBS for aggrecan sections and 3\% BSA for COLIIA1 sections were carried out, and secondary antibodies, donkey anti-rabbit IgG Alexa Fluor 546 (1:200, Thermo Fisher Scientific) for aggrecan and goat anti-rabbit IgG Alexa Fluor 546 

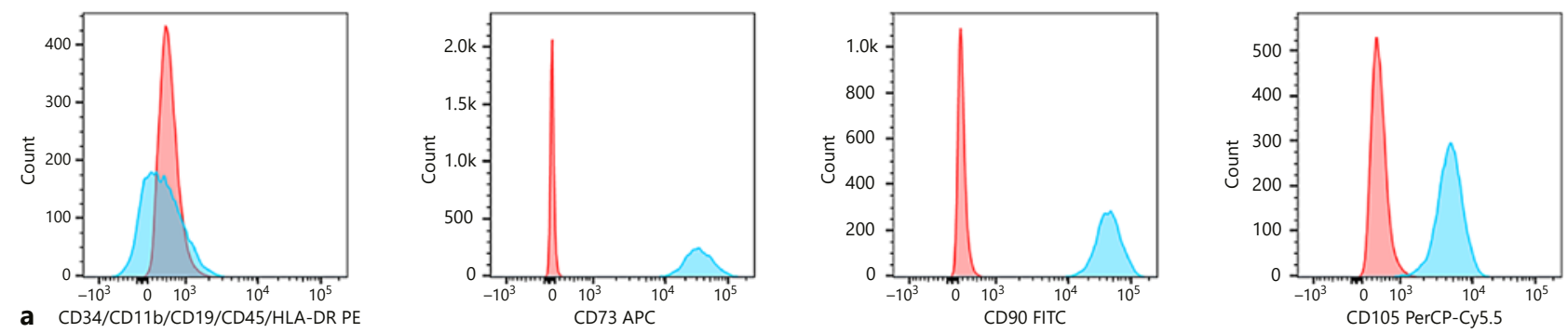

Cell viability/proliferation of DC pellets treated with different concentrations of MMP-1

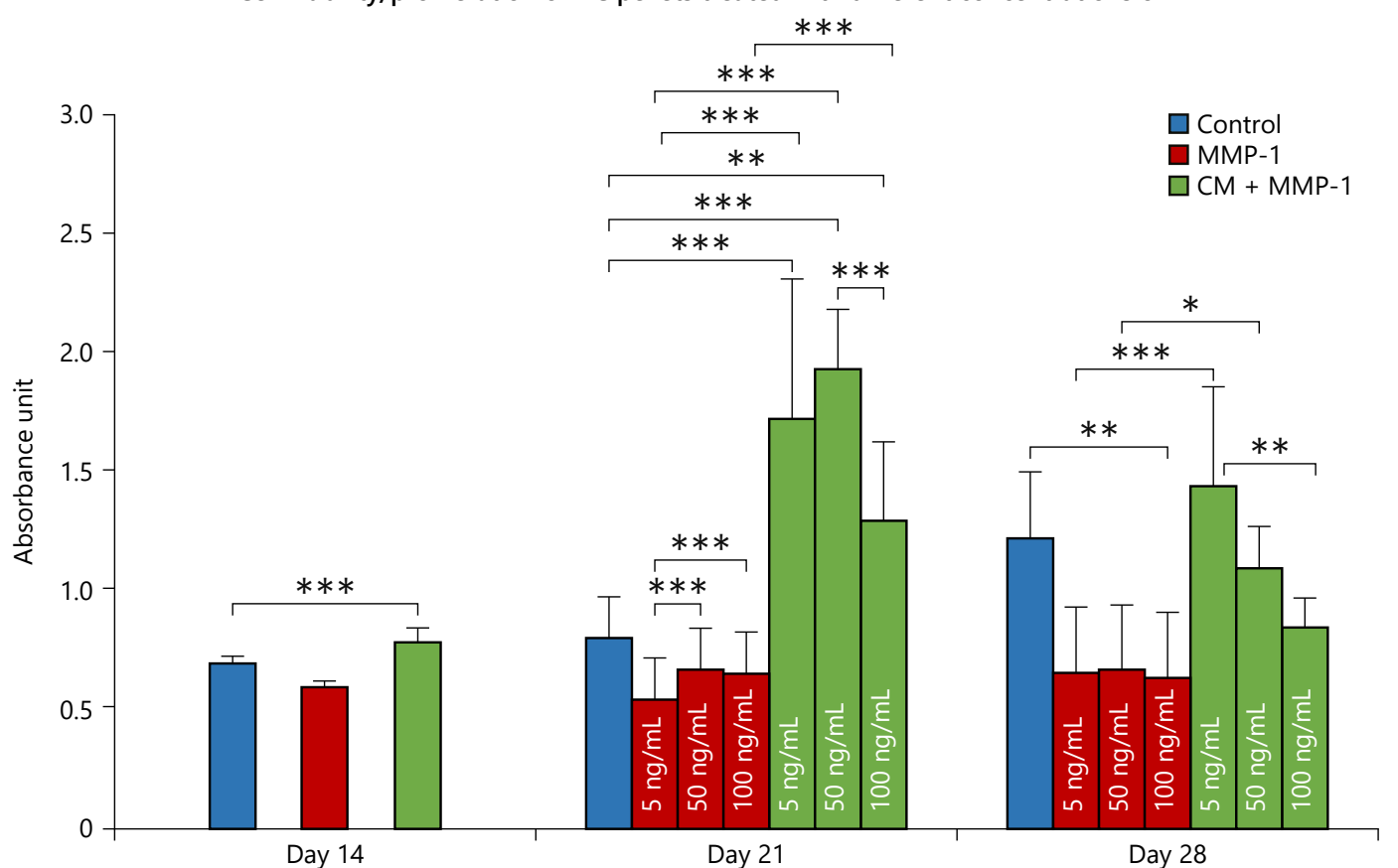

b

Day 14

Day 21

Day 28

Fig. 1. a Bone marrow-derived hMSCs exhibit the common MSC markers CD73, CD90, and CD105 and are negative for the hematopoietic markers CD45, CD34, CD11b, CD19, and HLA-DR (blue curve: antibody-stained sample; red curve: isotype control). b Cell viability and proliferation of DC pellets on days 7-28. The bar graphs show DC pellets stimulated with conditioned media (CM + MMP-1) and chondrogenic media (MMP-1) with addition of 5, 50, and $100 \mathrm{ng} / \mathrm{mL}$ of MMP-1 to each group on days $14-28$. DC pellets stimulated with chondrogenic media without the addition of MMP-1 served as a control. The result is presented in the unit of absorbance where the absorbance is directly proportional to the number of cells. Means \pm SEM. ${ }^{*} p<0.05,{ }^{* *} p<0.01$, $* * * p<0.001$.

(1:200, Thermo Fisher Scientific) for COLIIA1, were added. To enhance the signal for COLIIA 1 sections, the TSA plus cyanine 3 system kit (PerkinElmer, MA, USA) was used. ProLong ${ }^{\circledR}$ gold antifade mountant (DAPI; Thermo Fisher Scientific) nucleus counterstaining was performed. The samples were examined using fluorescence microscopy (Nikon Eclipse E600, Japan), and NIS Elements software (Nikon Metrology) was used to perform fluorescent intensity quantification and to determine the area of the pellets. The level of protein expression was presented as pixels $/ \mu \mathrm{m}^{2}$ ( $n=3$ with 2 technical replicates for each stimulation group).

\section{Statistical Analysis}

Statistical data are expressed as means \pm SEM. Analysis was conducted using Student's $t$ test for comparing means between 2 groups and multivariate ANOVA with Tukey post hoc test for multiple comparisons. Analysis was performed using SPSS 25.0 software (IBM SPSS Statistics, NY, USA). $p<0.05$ was considered statistically significant. 

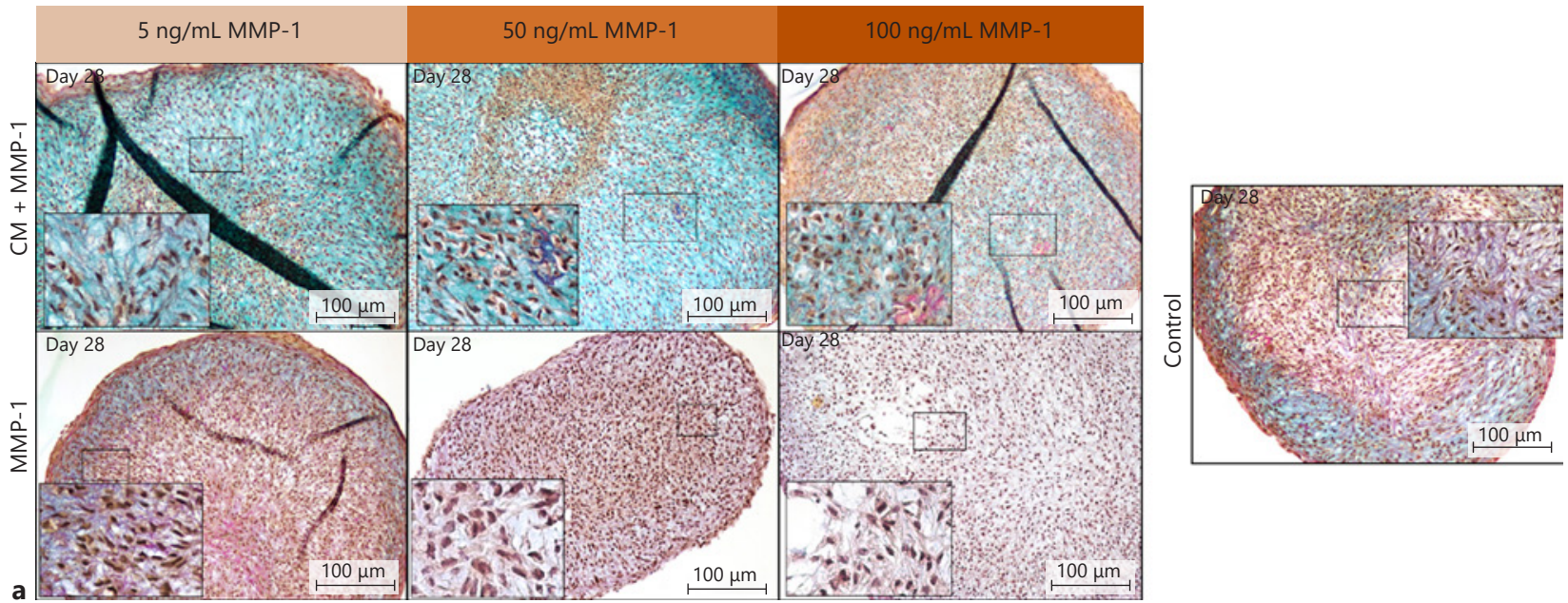

GAG production in DC pellets with treatment of MPP-1

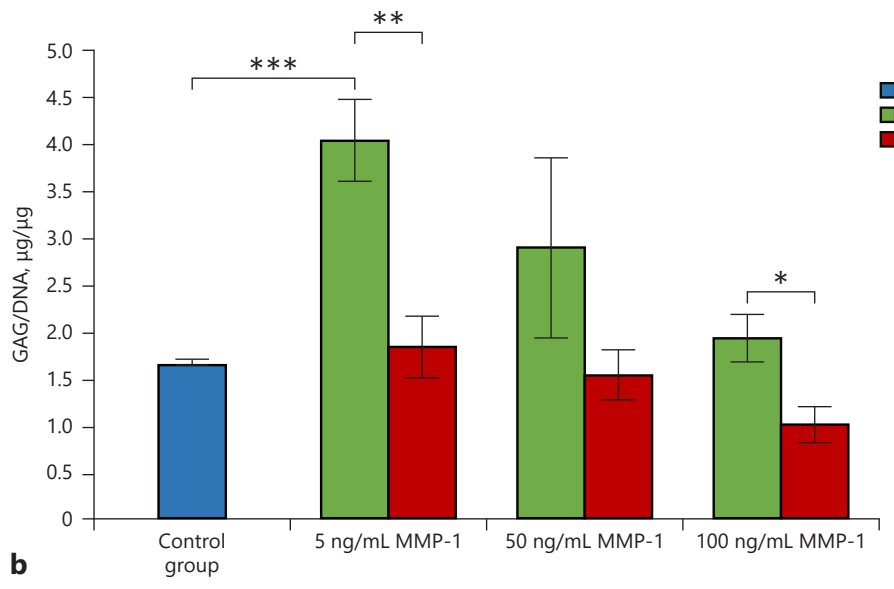

Fig. 2. a Histological staining of DC pellets stimulated with conditioned media (CM + MMP-1) and chondrogenic media (MMP-1) supplemented with 5, 50, and $100 \mathrm{ng} / \mathrm{mL}$ of MMP-1 to each group on days 14-28. DC pellets without the addition of MMP-1 served as a control. Alcian blue-van Gieson staining of DC pellets collected on day 28, where proteoglycan stained blue, collagen stained pink, and black dots represent cell nuclei. b Quantification of GAG production in DC pellets on day 28. Means \pm SEM. ${ }^{*} p<0.05,{ }^{* *} p<0.01,{ }^{* * *} p<0.001$.

\section{Results}

\section{MMP-1 Level in Disk Tissue}

The average concentration of MMP-1 detected in disk tissue from patients with IVD degeneration was found to be $151 \mathrm{ng} / \mathrm{mL}$ (range $84-254 \mathrm{ng} / \mathrm{mL}$ ), and a higher concentration of MMP- 1 was detected in grade $4 / 5$ disk tissue (Table 1).

\section{Characterization of hMSCs}

The surface markers CD73, CD90, and CD105 of hMSCs were detected, and the hematopoietic lineage markers CD45, CD34, CD11b, CD19, and HLA-DR were absent (Fig. 1a) in the hMSCs isolated from bone marrow aspirates (blue curve: antibody-stained sample, red curve: isotype control) confirming the phenotypic characteristics of hMSCs.

\section{Cell Proliferation/Viability of DC Pellets}

Significantly higher cell viability was observed in DC pellets stimulated with $\mathrm{CM}(0.8 \pm 0.1)$ compared to control $(0.7 \pm 0.02)$ pellets on day $14(p<0.001)$ (Fig. 1b). After the addition of MMP-1 on day 14, lower cell viability was observed in MMP- 1 groups $(0.5 \pm 0.1,0.7 \pm 0.1$, 

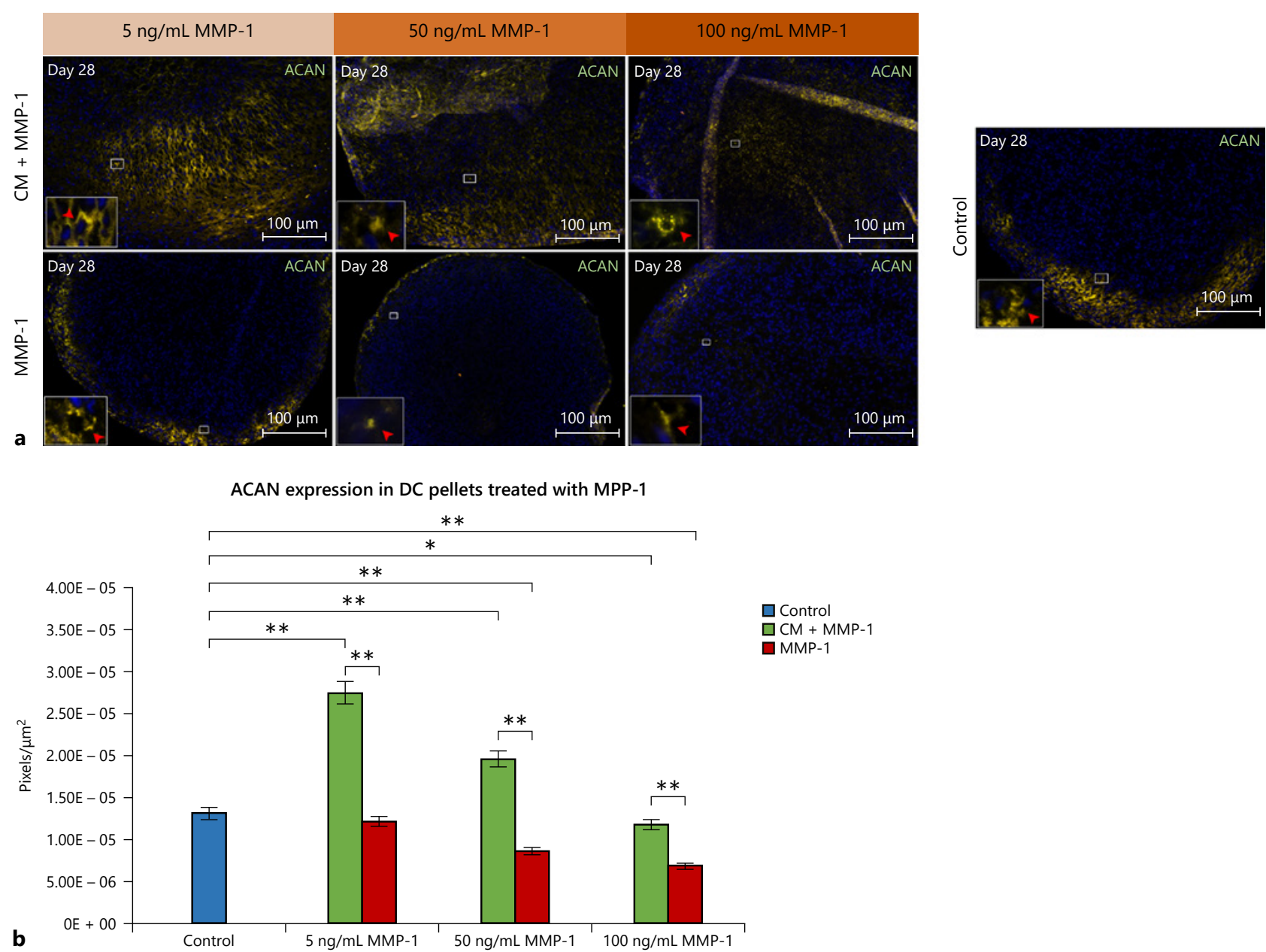

Fig. 3. a Expression of aggrecan (ACAN) in DC pellets harvested on day 28. The pellets were stimulated with conditioned media (CM + MMP-1) and chondrogenic media (MMP-1). MMP-1 (5, 50, and $100 \mathrm{ng} / \mathrm{mL}) \mathrm{was}$ added to all groups on days 14-28. DC pellets stimulated with chondrogenic media without the addition of MMP-1 served as a control. Green colors indicated by red arrowheads represent the expression of ACAN, and blue dots represent cell nuclei. b Bar graphs illustrate the level of ACAN-positive cells in the pellets. Means \pm SEM. ${ }^{*} p<0.05,{ }^{* *} p<0.01$.

and $0.7 \pm 0.1)$ compared to controls $(0.8 \pm 0.2)$ on day 21 . However, CM + MMP-1 groups $(1.7 \pm 0.6,1.9 \pm 0.3$, and $1.3 \pm 0.3)$ showed a significantly higher level of cell viability than MMP-1 and control groups $(p<0.001)$ at the same time point. Among the CM + MMP-1 groups, pellets stimulated with $100 \mathrm{ng} / \mathrm{mL}$ MMP-1 possessed significantly lower $(p<0.001)$ cell viability $(1.3 \pm 0.3)$ than the pellets stimulated with both lower MMP-1 concentrations $(1.7 \pm 0.6,1.9 \pm 0.3)$. On day 28 , cell viability in MMP-1 groups $(0.7 \pm 0.1,0.7 \pm 0.4$, and $0.6 \pm 0.2)$ was significantly lower $(p<0.001)$ than in the CM + MMP-1 $(1.4 \pm 0.1,1.1 \pm 0.2$, and $0.8 \pm 0.1$,$) and control (p<0.01)$ groups $(1.2 \pm 0.3)$. In $\mathrm{CM}+\mathrm{MMP}-1$ groups, significantly lower cell viability $(p<0.01)$ was observed with increased MMP-1 concentration.

\section{Histological Staining of the Pellets}

Alcian blue-van Gieson staining revealed less proteoglycan accumulation in DC pellets with increased concentration of MMP-1 (Fig. 2a). In CM + MMP-1 groups, pellet stimulated with $5 \mathrm{ng} / \mathrm{mL}$ of MMP-1 yielded the highest proteoglycan accumulation; in fact, the positive staining observed was even more pronounced than that of controls. However, the level decreased at $100 \mathrm{ng} / \mathrm{mL}$ 


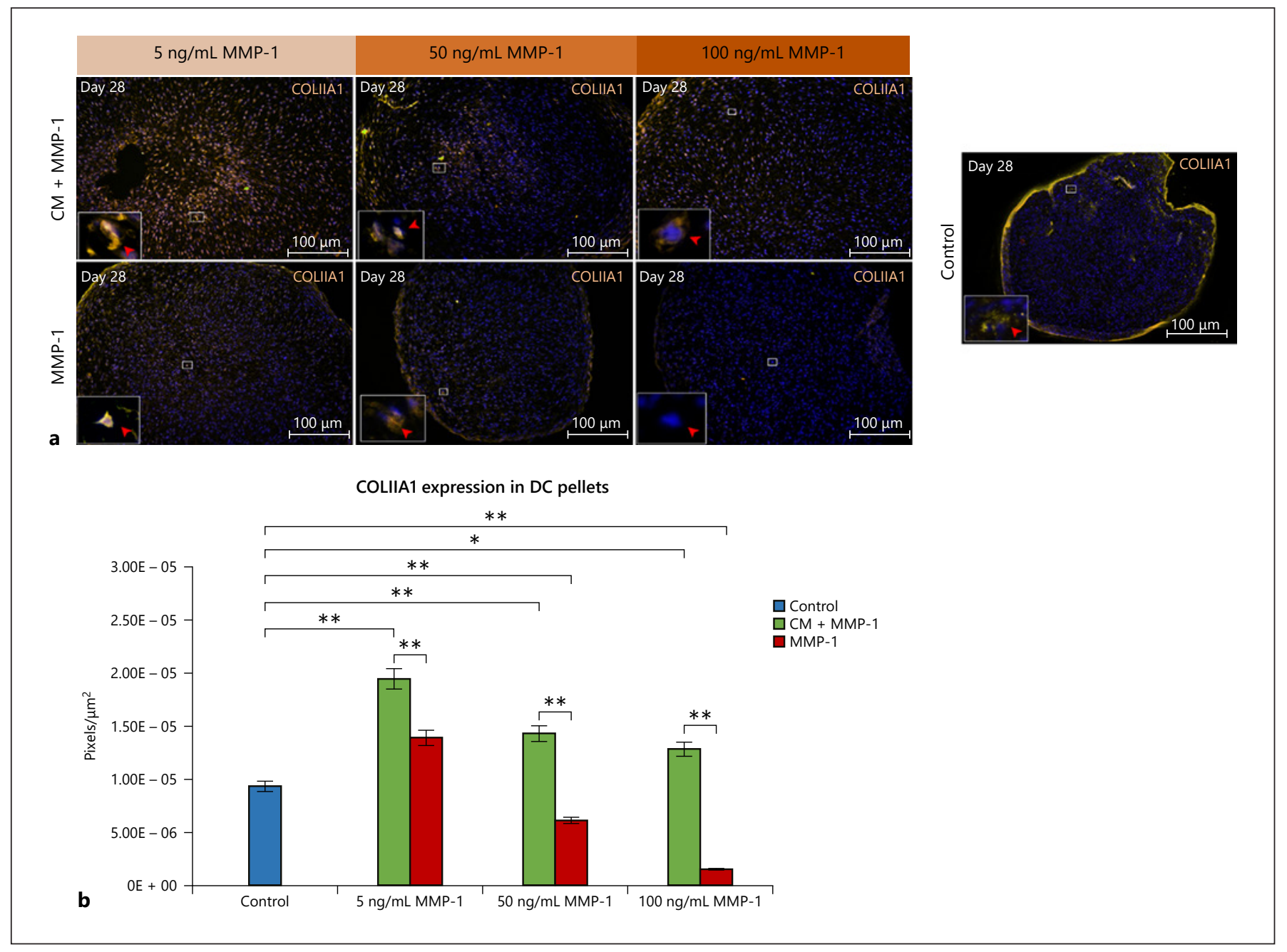

Fig. 4. a Expression of collagen type II (COLIIA1) in DC pellets collected on day 28. Pellets were stimulated with conditioned media (CM + MMP-1) and chondrogenic media (MMP-1). MMP-1 (5, 50 and $100 \mathrm{ng} / \mathrm{mL})$ was added to all groups on days 14-28. DC pellets stimulated with chondrogenic media without the addition of MMP-1 served as a control. Yellow color indicated by red arrowheads indicates the expression of COLIIA1, and blue dots represent cell nuclei. b The bar graphs illustrate the level of COLIIA1-positive cells in the pellets. Means \pm SEM. ${ }^{*} p<0.05,{ }^{* *} p<0.01$.

MMP-1. In MMP-1 groups, proteoglycan accumulation was observed at $5 \mathrm{ng} / \mathrm{mL} \mathrm{MMP-1}$, and little to none was observed at 50 and $100 \mathrm{ng} / \mathrm{mL}$ MMP-1.

\section{GAG Production in Pellets}

DC pellets in $\mathrm{CM}+\mathrm{MMP}-1$ groups yielded a higher amount of GAG than MMP-1 groups and controls (Fig. 2b). With $5 \mathrm{ng} / \mathrm{mL}$ MMP-1, the mean production of GAG in the CM + MMP-1 group was $4 \pm 0.4 \mu \mathrm{g} / \mu \mathrm{g}$, a significantly higher GAG level compared to the MMP-1 group $(p<0.01)$ with a mean of $1.8 \pm 0.3 \mu \mathrm{g} / \mu \mathrm{g}$ and controls with a mean of $1.6 \pm 0.06 \mu \mathrm{g} / \mu \mathrm{g}(p<0.001)$. A grad- ual decrease in GAG production was observed for all groups with increased MMP-1 concentration. The CM + MMP-1 groups yielded the lowest GAG $(1.9 \pm 0.2501 \mu \mathrm{g} /$ $\mu \mathrm{g})$ at $100 \mathrm{ng} / \mathrm{mL}$ MMP-1, where the GAG produced was half that at $5 \mathrm{ng} / \mathrm{mL}$ MMP-1, but this was still significantly higher $(p<0.05)$ than that of the $100 \mathrm{ng} / \mathrm{mL}$ MMP-1 group $(1 \pm 0.2 \mu \mathrm{g} / \mu \mathrm{g})$.

\section{Immunohistochemistry}

Aggrecan Expression

Aggrecan expression was observed in all groups (Fig. 3a). However, significantly higher expression $(p<$ 
0.01) was detected in CM + MMP-1 than MMP-1 groups (Fig. 3b). A gradual decrease in expression levels was observed with increased MMP-1 concentrations in all groups. For the CM + MMP-1 group, with $100 \mathrm{ng} / \mathrm{mL}$ MMP-1 the mean fluorescence intensity was $1.2 \times 10^{-5} \pm$ $6 \times 10^{-6}$ pixels $/ \mu \mathrm{m}^{2}$. This was half the intensity detected for the CM + MMP-1 group with $5 \mathrm{ng} / \mathrm{mL}$ MMP-1 $(2.8 \times$ $10^{-5} \pm 2 \times 10^{-6}$ pixels $\left./ \mu \mathrm{m}^{2}\right)$. However, this was still significantly higher $(p<0.05)$ than the MMP-1 group with $100 \mathrm{ng} / \mathrm{mL} \mathrm{MMP-1}\left(5 \times 10^{-6} \pm 3 \times 10^{-6}\right.$ pixels $\left./ \mu \mathrm{m}^{2}\right)$.

\section{COLIIA1 Expression}

Expression of COLIIA1 was observed in all groups (Fig. 4a). Significantly higher expression of COLIIA1 $(p<0.01)$ was observed in CM + MMP-1 than MMP-1 groups (Fig. 4b).

Mean fluorescence intensity was $1.9 \times 10^{-5} \pm 2 \times 10^{-6}$ pixels $/ \mu \mathrm{m}^{2}$ for the $\mathrm{CM}+\mathrm{MMP}-1$ group at $5 \mathrm{ng} / \mathrm{mL} \mathrm{MMP}$ 1 where the intensity decreased at $50 \mathrm{ng} / \mathrm{mL}$ MMP-1 to $1.4 \times 10^{-5} \pm 2 \times 10^{-6}$ pixels $/ \mu \mathrm{m}^{2}$ and at $5 \mathrm{ng} / \mathrm{mL}$ to $1.3 \times$ $10^{-5} \pm 3 \times 10^{-6}$ pixels $/ \mu \mathrm{m}^{2}$. However, this was still significantly higher $(p<0.01)$ than that of the MMP-1 group stimulated with $100 \mathrm{ng} / \mathrm{mL}$ MMP-1, where almost no expression was observed in the MMP-1 group at $100 \mathrm{ng} / \mathrm{mL}$.

\section{Discussion}

Findings from this study quantified the human concentrations of MMP-1 in degenerated disk tissue and demonstrated that CM from hMSCs could counteract the matrix-degrading effects of MMP- 1 up to $50 \mathrm{ng} / \mathrm{mL}$ concentrations in this $3 \mathrm{D}$ in vitro model. This suggests that CM could potentially be used to treat or halt early stages of IVD degeneration.

Cell viability and proliferation of DCs were promoted by CM groups with more proteoglycan and GAG production than MMP-1 and control groups. However, lower ECM production was observed with increased MMP-1 concentrations.

Detection of high MMP-1 concentrations in Pfirrmann grade 4/5 degenerated disk tissue suggested that MMP- 1 concentration in the disk tissue is a marker of the severity of IVD degeneration. The regulation of ECM synthesis and degradation in the IVDs is facilitated by MMPs [Deng et al., 2015], and up-regulation of MMPs is connected to ECM degradation and IVD damage [Rastogi et al., 2013; Li et al., 2016]. High levels of MMP-1 were also reported in blood serum of patients with IVD degeneration [Deng et al., 2015]; in fact, a higher level was detected in patients with severe IVD degeneration compared to mild and moderate ones [Gruber et al., 2012; Xu et al., 2014; Huang et al., 2018]. However, further investigation in larger sample sizes with healthy control disks is needed to confirm the MMP-1 results in IVD tissue.

Results from a previous study revealed that stimulation of CM on DCs enhanced cell viability and ECM production, and analysis of CM constituents identified the presence of multiple signaling proteins along with TIMP1, an antagonist of MMP-1 [Hingert et al., 2020]. It is, therefore, of interest to investigate if CM could mitigate the degenerative effect of MMP-1. In this in vitro study, CM from hMSCs demonstrated that it can combat the ECM degradation of MMP-1 while enabling cell proliferation and maintaining cell viability. Detection of more viable cells in DC pellets treated with CM at lower MMP1 concentration could be due to the fact that cell proliferation can be best facilitated at low MMP-1 concentration [He et al., 2017]. The detection of higher numbers of viable cells in CM groups (CM + MMP-1) compared to the MMP-1 and control groups also suggests that CM possessed factors that facilitated the cells to be viable and proliferative throughout the experimental time points. This implies that CM from hMSCs promoted cell viability and proliferation in DCs isolated from degenerated IVD tissue.

The presence of MMP-1 alone seemed to negatively affect cell viability and proliferation in DC pellets as DCs treated with MMP-1 alone had significantly lower viable cells than controls. It can be speculated that addition of MMP-1 degraded the collagen matrix in the pellets making it hard for the cells to interact with ECM to maintain viability as the loss of ECM structure decreases cell viability [Tchetverikov et al., 2005]. The notion is supported by the expression of COLIIA1 in MMP-1 groups where lower expression was detected with increased MMP-1 concentration. Likewise, a similar pattern was observed with aggrecan expression in the MMP-1 groups. In addition to its collagen degradation ability, MMP-1 has also been reported to break down aggrecan in in vitro models [Di Cesare et al., 2017; Goldring et al., 2017]. Aggrecan and COLIIA1 are important ECM components, and through the production of aggrecan, cells are enabled to interact with hyaluronan to further produce proteoglycan aggregates [Mwale et al., 2004; Roughley, 2004]. It was likely due to this that low proteoglycan accumulation and GAG production was observed in the MMP-1 groups. The MMP- 1 concentrations $(5,50$, and $100 \mathrm{ng} / \mathrm{mL}$ ) were selected with the aim to evaluate the efficacy of the enzyme starting from a low concentration to a concentration that 
represents approximately grade $3 / 4$ disks. Further, the tissue concentration is not directly translational to an in vitro culture system where the substance in cell media is directly exposed to the cells. These were the reasons why MMP-1 at concentrations below the average tissue concentrations detected were chosen in the in vitro testing. It was evident that CM had a remarkable effect on 5 and 50 $\mathrm{ng} / \mathrm{mL}$ MMP-1, but with $100 \mathrm{ng} / \mathrm{mL}$, proteoglycan accumulation and GAG production of DC decreased. Likewise, the lowest levels of COLIIA1 and aggrecan expression were observed in the $100 \mathrm{ng} / \mathrm{mL}$ MMP-1 compared to the lower MMP-1 concentrations. CM have been demonstrated to delay degeneration in many disease models [Cosenza et al., 2017; Chen et al., 2019]. The microenvironment seems to have a strong impact on the hMSC secretome as hMSCs secrete different factors based on their surroundings [Maffioli et al., 2017]. This could be the reason why enhanced chondrogenic activity was observed in coculture and proinflammatory cytokine pretreatment models, which has been believed to be mainly due to cellcell communication (paracrine signaling) and environmental stimuli, respectively [Svanvik et al., 2010; Hingert et al., 2018, 2019]. hMSCs are also known to secrete extracellular vesicles, including exosomes delivering various bioactive factors [Cheng et al., 2018]. This suggests that CM holds the potential to remedy early stages of IVD degeneration, and disks with a relatively limited degeneration degree (Pfirrmann grade 2-3) could potentially be influenced. One of the limitations of the study is the fact that 3D pellet models do not completely reflect the in vivo environment of the disk, and hence further investigation in disk degeneration models in vivo are needed.

To conclude, this study quantified the human level of MMP-1 in degenerated disk tissue and demonstrated that CM from hMSCs could combat matrix-degrading properties of MMP-1 in this in vitro model. Cell viability and ECM production were promoted in the CM groups even in the presence of MMP-1; however, with increasing MMP-1 concentration, the potency of CM decreased. The results imply that CM could possibly be used to successfully develop an effective therapy for early-stage IVD degeneration.

\section{Statement of Ethics}

All human tissue and cells were collected with ethical permission (approved by the Regional Ethical Review Board at Sahlgrenska Academy, Gothenburg University, Gothenburg, Sweden; Dnr 532-04) and with informed consent from the patients.

\section{Conflict of Interest Statement}

The authors declare that they have no competing interests.

\section{Funding Sources}

The study was financed by grants from the Swedish state under the agreement between the Swedish government and the country councils, the Alf agreement, and the Dr. Felix Neubergh Foundation.

\section{Author Contributions}

P.N. performed cell cultures, biochemical analysis, histology, and image analysis and contributed to manuscript writing. D.H. designed the studies, supervised P.N. with the experiments, analyzed and compiled the results, and was a major contributor to manuscript writing. K.E. performed flow cytometry and compiled some of the results. A.B. collected tissue samples for the experiment and provided input for the study. H.B. collected tissue samples from patients and provided the samples for the studies, helped design the studies, interpreted results, and contributed to manuscript writing. All authors read and approved the manuscript.

\section{References}

Airaksinen O, Brox JI, Cedraschi C, Hildebrandt J, Klaber-Moffett J, Kovacs F, et al. Chapt 4. European guidelines for the management of chronic nonspecific low back pain. Eur Spine J. 2006 Mar; 15 Suppl 2:S192-300.

Chen W, Sun Y, Gu X, Hao Y, Liu X, Lin J, et al. Conditioned medium of mesenchymal stem cells delays osteoarthritis progression in a rat model by protecting subchondral bone, maintaining matrix homeostasis, and enhancing autophagy. J Tissue Eng Regen Med. 2019 Sep;13(9):1618-28.
Cheng X, Zhang G, Zhang L, Hu Y, Zhang K, Sun $\mathrm{X}$, et al. Mesenchymal stem cells deliver exogenous miR-21 via exosomes to inhibit nucleus pulposus cell apoptosis and reduce intervertebral disc degeneration. J Cell Mol Med. 2018 Jan;22(1):261-76.

Cosenza S, Ruiz M, Toupet K, Jorgensen C, Noël D. Mesenchymal stem cells derived exosomes and microparticles protect cartilage and bone from degradation in osteoarthritis. Sci Rep. 2017 Nov;7(1):16214.
Deng B, Ren JZ, Meng XQ, Pang CG, Duan GQ, Zhang JX, et al. Expression profiles of MMP-1 and TIMP-1 in lumbar intervertebral disc degeneration. Genet Mol Res. 2015 Dec;14(4): 19080-6.

Di Cesare PE, Haudenschild DR, Samuels J, Abramson SB. Pathogenesis of Osteoarthritis; in Firestein GS, Budd RC, Gabriel SE, McInnes IB, O'Dell JR (eds): Kelley and Firestein's Textbook of Rheumatology, ed 10. Amsterdam: Elsevier; 2017. Chapt 98. pp. $1685-$ 1704.e1688. 
Ekman M, Jönhagen S, Hunsche E, Jönsson L. Burden of illness of chronic low back pain in Sweden: a cross-sectional, retrospective study in primary care setting. Spine. 2005 Aug; 30(15):1777-85.

Goldring MB, Culley KL, Wondimu E, Otero M. Cartilage and Chondrocytes; in Firestein, G.S., R.C. Budd, S.E. Gabriel, I.B. McInnes, J.R. O'Dell (eds): Kelley and Firestein's Textbook of Rheumatology, ed 10. Amsterdam: Elsevier; 2017. Chapt 3. p. 34-59.e33.

Goupille P, Jayson MI, Valat JP, Freemont AJ. Matrix metalloproteinases: the clue to intervertebral disc degeneration? Spine. 1998 Jul; 23(14):1612-26.

Gruber HE, Hoelscher GL, Ingram JA, Hanley EN Jr. Matrix metalloproteinase-26, a novel MMP, is constitutively expressed in the human intervertebral disc in vivo and in vitro. Exp Mol Pathol. 2012 Feb;92(1):59-63.

He X, Dai J, Fan Y, Zhang C, Zhao X. Regulation function of MMP-1 downregulated by siRNA on migration of heat-denatured dermal fibroblasts. Bioengineered. 2017 Nov;8(6):686-92.

Hingert D, Barreto Henriksson $\mathrm{H}$, Baranto A, Brisby H. BMP-3 promotes matrix production in co-cultured stem cells and disc cells from low back pain patients. Tissue Eng Part A. 2020 Jan;26(1-2):47-56.

Hingert D, Barreto Henriksson H, Brisby H. Human Mesenchymal Stem Cells Pretreated with Interleukin-1 $\beta$ and Stimulated with Bone Morphogenetic Growth Factor-3 Enhance Chondrogenesis. Tissue Eng Part A. 2018 May;24(9-10):775-85.

Hingert D, Nawilaijaroen P, Aldridge J, Baranto A, Brisby H. Investigation of the Effect of Secreted Factors from Mesenchymal Stem Cells on Disc Cells from Degenerated Discs. Cells Tissues Organs. 2019;208(1-2):76-88.

Huang X, Hou Y, Zhong L, Huang D, Qian H, Karperien M, et al. Promoted Chondrogenesis of Cocultured Chondrocytes and Mesenchymal Stem Cells under Hypoxia Using Insitu Forming Degradable Hydrogel Scaffolds. Biomacromolecules. 2018 Jan;19(1):94-102.

Johnson ZI, Schoepflin ZR, Choi H, Shapiro IM, Risbud MV. Disc in flames: roles of TNF- $\alpha$ and IL- $1 \beta$ in intervertebral disc degeneration. Eur Cell Mater. 2015 Sep;30:104-16; discussion 116-7.
Kay AG, Long G, Tyler G, Stefan A, Broadfoot SJ, Piccinini AM, et al. Mesenchymal Stem CellConditioned Medium Reduces Disease Severity and Immune Responses in Inflammatory Arthritis. Sci Rep. 2017 Dec;7(1):18019.

Leckie SK, Bechara BP, Hartman RA, Sowa GA, Woods BI, Coelho JP, et al. Injection of AAV2-BMP2 and AAV2-TIMP1 into the nucleus pulposus slows the course of intervertebral disc degeneration in an in vivo rabbit model. Spine J. 2012 Jan;12(1):7-20.

Li Y, Li K, Han X, Mao C, Zhang K, Zhao T, et al. The imbalance between TIMP3 and matrixdegrading enzymes plays an important role in intervertebral disc degeneration. Biochem Biophys Res Commun. 2016 Jan;469(3):507-14.

Mwale F, Roughley P, Antoniou J. Distinction between the extracellular matrix of the nucleus pulposus and hyaline cartilage: a requisite for tissue engineering of intervertebral disc. Eur Cell Mater. 2004 Dec;8:58-63.

Pockert AJ, Richardson SM, Le Maitre CL, Lyon M, Deakin JA, Buttle DJ, et al. Modified expression of the ADAMTS enzymes and tissue inhibitor of metalloproteinases 3 during human intervertebral disc degeneration. Arthritis Rheum. 2009 Feb;60(2):482-91.

Rastogi A, Kim H, Twomey JD, Hsieh AH. MMP2 mediates local degradation and remodeling of collagen by annulus fibrosus cells of the intervertebral disc. Arthritis Res Ther. 2013 Apr;15(2):R57.

Roughley PJ. Biology of intervertebral disc aging and degeneration: involvement of the extracellular matrix. Spine. 2004 Dec;29(23):2691-9.

Somoza RA, Welter JF, Correa D, Caplan AI. Chondrogenic differentiation of mesenchymal stem cells: challenges and unfulfilled expectations. Tissue Eng Part B Rev. 2014 Dec; 20(6):596-608.

Svanvik T, Henriksson HB, Karlsson C, Hagman M, Lindahl A, Brisby H. Human disk cells from degenerated disks and mesenchymal stem cells in co-culture result in increased matrix production. Cells Tissues Organs. 2010;191(1):2-11.
Tchetverikov I, Lohmander LS, Verzijl N, Huizinga TW, TeKoppele JM, Hanemaaijer $\mathrm{R}$, et al. MMP protein and activity levels in synovial fluid from patients with joint injury, inflammatory arthritis, and osteoarthritis. Ann Rheum Dis. 2005 May;64(5):694-8.

van Hooff ML, van Loon J, van Limbeek J, de Kleuver M. The Nijmegen decision tool for chronic low back pain. Development of a clinical decision tool for secondary or tertiary spine care specialists. PLoS One. 2014 Aug; 9(8):e104226

Vo NV, Hartman RA, Yurube T, Jacobs LJ, Sowa GA, Kang JD. Expression and regulation of metalloproteinases and their inhibitors in intervertebral disc aging and degeneration. Spine J. 2013 Mar;13(3):331-41.

Wang Y, Jiang L, Dai G, Li S, Mu X. Bioinformatics analysis reveals different gene expression patterns in the annulus fibrosis and nucleus pulpous during intervertebral disc degeneration. Exp Ther Med. 2018 Dec;16(6):5031-40.

Xu H, Mei Q, Xu B, Liu G, Zhao J. Expression of matrix metalloproteinases is positively related to the severity of disc degeneration and growing age in the East Asian lumbar disc herniation patients. Cell Biochem Biophys. 2014 Nov;70(2):1219-25.

Zeckser J, Wolff M, Tucker J, Goodwin J. Multipotent Mesenchymal Stem Cell Treatment for Discogenic Low Back Pain and Disc Degeneration. Stem Cells Int. 2016;2016:3908389.

Zhang JF, Wang GL, Zhou ZJ, Fang XQ, Chen S, Fan SW. Expression of Matrix Metalloproteinases, Tissue Inhibitors of Metalloproteinases, and Interleukins in Vertebral Cartilage Endplate. Orthop Surg. 2018 Nov; 10(4):30611.

Zou J, Huang GF, Zhang Q, Gao Y, Wang BY. Effects of electroacupuncture stimulation of "Jiaji" (EX-B 2) on expression of matrix metalloproteinase-13 and tissue inhibitor of metalloproteinase- 1 in intervertebral disc tissue in rabbits with lumbar intervertebral disc degeneration. Zhen Ci Yan Jiu. 2014 Jun;39(3): 192-7. Chinese. 